\title{
Does cultural distance affect online review ratings? Measuring international customers' satisfaction with services leveraging digital platforms and big data
}

\author{
Marcello M. Mariani ${ }^{1} \cdot$ Michela Matarazzo $^{2}$
}

Accepted: 14 September 2020 / Published online: 18 November 2020

(c) The Author(s) 2020

\begin{abstract}
The advent and development of digital platforms has helped enhance the international visibility of brands, products and services, and has also introduced a proliferation of online reviews. This study develops a big data analysis of customer online reviews of hospitality services to gauge the extent to which the cultural distance among service providers and their customers influences online review ratings. By examining almost 715,000 online reviews written by hotel customers from more than 100 different nationalities, the effect of national cultural differences among service customers and providers (namely cultural distance) on online review ratings is innovatively scrutinized. The paper, by considering reviewers' behavioral features, demographics, and trip-related factors, reveals that the effect of national cultural distance on online review ratings is negative. Several implications for practitioners are also discussed.
\end{abstract}

Keywords Big data $\cdot$ Digital platforms $\cdot$ eWOM $\cdot$ Online reviews $\cdot$ Cultural distance $\cdot$ International customers

\section{Introduction}

In recent years, electronic word-of-mouth (eWOM) recommendations in the guise of online consumer reviews have recorded an exponential growth. Today, consumer purchase intentions are increasingly influenced by online reviews, perceived as

Marcello M. Mariani

m.mariani@henley.ac.uk

Michela Matarazzo

m.matarazzo@unimarconi.it

1 Henley Business School, University of Reading, Oxfordshire,

Greenlands, Henley on Thames RG9 3AU, UK

2 Department of Economic and Business Sciences, Università degli Studi G. Marconi, Via Plinio, 44, Rome, Italy 
a credible source by consumers (Ludwig et al. 2013; Zhu and Zhang 2010). Several scholars in multiple disciplines (including marketing, computer science, and management science) have examined the extent to which online consumer reviews impact consumer evaluations (Jin et al. 2014; Singh et al. 2014) and firm performance (Mariani and Borghi 2020; Mariani and Visani 2019; Yang et al. 2018).

Technological and digital developments brought about by the 4th industrial revolution (Mariani and Borghi 2019; Pillai et al. 2020) have had an impact on and transformed the travel and tourism industry significantly. Online consumers looking for accommodation and hospitality services increasingly refer to online reviews from Online Travel Agencies (OTAs) like Booking.com and independent review platforms like TripAdvisor, to assess hospitality services. In parallel, hospitality companies use online reviews and ratings to inform their marketing decisions and protect their online reputation (Xie et al. 2016).

As a result of the advent and consolidation of digital technologies, international tourists have more opportunities than ever to interrelate with people from different nations who display distinctively diverse cultural backgrounds online before, during and after their online purchases (Mariani et al. 2019a). For this reason, cultural distance among service providers and service customers plays apparently a considerable and complex role in the online environment.

A rich body of literature has examined online consumer behavior and the related eWOM from a cross-cultural perspective in different verticals and industries, including retail, banking and the mobile telecommunication sector (e.g. Yun et al. 2008).

Seminal studies on the effects of cultural factors on consumer perceptions of hospitality services are mainly aimed at comparing Eastern vs Western consumers (see Mattila 1999, 2000; McCleary et al. 1998) to emphasize differences in expectations, attitudes, evaluations, behaviors, and satisfaction of hospitality service consumers.

Nevertheless, the impact of cultural factors on the online evaluation of hotel services remains relatively unexplored theoretically and empirically, except for a few recent studies. One group of studies (Liu et al. 2017; Mariani et al. 2019a; Schuckert et al. 2015b) investigates the effects of language used for reviewing purposes on online consumer behaviors and ratings after the hospitality service encounters. Another study (Gao et al. 2018), finds that the power distance of reviewers negatively affects their online hotel ratings.

However, so far, no attempt has been made to answer the ensuing research question: To what extent does cultural distance among service customers and service providers affect international customers' online evaluation (i.e. online ratings) after hospitality service consumption? To address this question and achieve generalizability of the findings, we methodologically leverage a big data analytical approach to the study of international customers' online reviews of hospitality services. More specifically, we retrieved and analysed the overall population of online reviews (i.e. more than 0.7 million online reviews) posted by international customers from 101 different nationalities that consumed hotel services in London, the third most popular destination for international tourists worldwide (European Cities Marketing 2018).

To address the question above, the paper is structured as follows: in Sect. 2 we review the relevant literature pertaining to eWOM, and cross-cultural studies in 
marketing and hospitality marketing, and develop the main research hypothesis. In Sect. 3 we illustrate the data and methods, while in Sect. 4 we present the findings and Sect. 5 considers several theoretical and empirical implications. In Sect. 6 we draw our conclusions, discuss the limitations and offer insights for promising future investigations.

\section{Literature review and hypothesis development}

\subsection{Online reviews, eWOM and digital platforms in customer decision-making}

The development and consolidation of digital technologies over the last 40 years has profoundly affected consumer behaviors and marketing channels. With the widespread adoption of the Internet, consumers increasingly compare products, services, transport methods, and payment alternatives based on the information available, for free, through search engines and company websites (Key 2017).Digital platforms and, more specifically, online review platforms modify the way consumers interact with companies and brands, and with each other (Breidbach et al. 2014; CasadesusMasanell and Hałaburda 2014; Gensler et al. 2013; Parker et al. 2016; Rowley 2008).

Today, consumers are particularly active on digital platforms and produce usergenerated content (UGC) defined as "media content created or produced by the general public, rather than paid professionals and primarily distributed on the Internet" (Daughtery et al. 2008: p. 16). UGC can be in the guise of text, audio, or video (Ek Styvén et al. 2020). One form of UGC is represented by online reviews and has become the object of eWOM studies. Hennig-Thurau et al. (2004) define eWOM communication as customers' desire to share their opinions on (and experiences with) products, services, and brands with a potentially high number of other online consumers.

Online consumer reviews are mechanisms enabled by digital platforms through which users rate (usually with a different number of stars) and express their written judgment and evaluation on previously purchased items in order to support others during their buying process (Appelt 2010). In this context, consumers who read consumer reviews may consider a variety of factors before making their purchase decisions, including review valence (i.e. the numerical rating or score of the review), review variance (i.e. the degree of consensus and consistency among the ratings of a specific online offering (Langan et al. 2017).

In the travel, tourism and hospitality sector, eWOM and online reviews play a critical role as consumers use eWOM before the purchasing process of risky services whose attributes cannot be evaluated easily ex ante (Gretzel and Yoo 2008). We refer to Schuckert et al. (2015a) for an extensive examination of the role of online reviews in the hotel sector. However, we could classify online review studies roughly into two macro-clusters Cantallops and Salvi (2014): those looking at the drivers of eWOM and those examining the impact of eWOM. Within the former cluster, some studies have explored and examined the determinants of online review features, including trust (Filieri et al. 2015) and acceptance predictors such as usefulness and ease of use (Ayeh et al. 2013; Mariani et al. 2019c). Within the 
latter cluster, works have analysed the impacts of eWOM from online reviews on the performance of hospitality firms (Mariani and Visani 2019; Yang et al. 2018). In several of these studies it has been argued that online review ratings are a proxy not only of service quality but also of online satisfaction (Engler et al. 2015) and while several studies have focused on overall ratings, others have also measured individual service attributes (e.g. Borghi and Mariani 2020; Limberger et al. 2014). However, not many studies have tried to contribute to the area at the intersection between eWOM and consumer cultural differences in hospitality services. As the cultural background of a consumer can make a difference in the way s/he evaluates a hospitality service, in the ensuing section we review studies that take into account how cultural differences can generate differentiated online consumer perceptions, evaluations and behaviors.

\subsection{Cross-cultural studies and online consumer behavior}

As e-commerce continues to expand globally, triggered by the development of digital technologies, and consumers become increasingly dependent on the opinions engendered by current online customers, one challenge for firms that cater to international customers is to determine if, and to what extent, national culture (and, therefore, cultural differences) is reflected in eWOM. Consequently, national culture is a key aspect to investigate further; indeed consumers from distinctively different cultures might evaluate the very same economic offering, be it a product or service, differently.

Previous research has shown that in social systems characterized by uncertainty avoidance and high collectivism it is likely that consumers might be more motivated to help their peer consumers and seek information from them. Hennig-Thurau et al. (2004) report a collectivism tendency among German consumers and "concern for other consumers" represented one of the major drivers for message posting behavior. Chau et al. (2002) empirically observe that online consumers in Hong Kong are more interested in the Internet's social features than their U.S. counterparts (who have a utilitarian approach to the information and the medium). Singh et al. (2003) find more uncertainty reduction features on Chinese websites than on U.S. ones, to accommodate different degrees of uncertainty avoidance. Consistently, Yun et al. (2008) observe that Korean online marketers take advantage of Korean customers' higher adoption of consumer reviews than online U.S. retailers. Tang (2017) finds that within individualistic cultures, positively valenced reviews on products sourced from developed countries are given less attention than reviews on products from developing countries and, in countries characterized by high power distance, negative reviews on the price of products from emerging markets have positive effects on sales. Deploying restaurant consumption data, Bagozzi et al. (2000) find that individualism influences purchase decisions when eating with friends, but not when alone; the effects of attitudes, subjective norms, and past behavior on intentions are greater for consumers from individualist countries such as the U.S., compared to those in more collectivist countries such as China, Japan, and Italy. Furthermore, studies conducted by Yamagishi et al. (1998), Allik and Realo (2004), Huff and 
Kelley (2003), and Van Hoorn (2015) all observe that in individualist countries (such as the U.S.), online customers tend to demonstrate a higher propensity to trust than those consumers in collectivist cultures. Schumann et al. (2010) find that consumers from high uncertainty avoidance cultures are more motivated to seek advice or assurance from eWOM to reduce perceived ambiguity and uncertainty than consumers from low uncertainty avoidance cultures. In contrast, shoppers from low uncertainty avoidance cultures are more willing to take risk and may totally disregard eWOM.

In hospitality marketing literature, only a handful of studies have analysed the role of national culture on eWOM in online settings (e.g. Mariani et al. 2019b; Mariani and Predvoditeleva 2019). All these studies embrace a "direct measurement approach" (Huang and Crotts 2019) to the examination of cultural factors on consumer behavior. In other words, rather than measuring differences in consumers' evaluations of hospitality services and interpreting them ex post, based on cultural frameworks (e.g. the Hofstede's cultural framework), they have used specific cultural variables (such as power distance and, more generally, the Hofstede's framework) to shed light on online ratings. Below, we focus on the relevant literature at the intersection between eWOM and cultural studies in hospitality to shape and formulate our hypothesis.

\subsection{Hypothesis development}

Starting in the 1990s, cross-cultural analyses have been conducted aimed at comparing evaluations, attitudes, and expectations of hotel customers from Western countries vs. hotel customers from Eastern countries (e.g. Chen et al. 2012; Reisinger and Turner 1999).

The majority of these were developed leveraging research design, such as experiments or field studies which included a relatively small number of hotel customers (200 to 300), from a few nationalities (typically two and, more rarely, three). The results of this scholarly work were discussed and interpreted by deploying a theoretical framework designed in the 1980s by scientist Geert Hofstede (Hofstede 1980), who defined culture as "collective programming of the mind" (Hofstede 2011, p. 3 ), distinguishing the members of a specific group from other people. The underlying assumption of the framework is that different national cultures possess different cultural features and these can be measured using a range of distinctively different "dimensions". Originally, Hofstede identified four distinctively different cultural dimensions: power distance (PD), individualism (IDV), masculinity (MAS), and uncertainty avoidance (UA). Subsequently, he complemented these dimensions with long-term orientation (LTO) and indulgence (IND) (Hofstede 2001). Power distance (PD) is defined as "the degree to which the less powerful members of a society accept and expect that power is distributed unequally". Individualism (IDV) is concerned with "a preference for a loosely-knit social framework in which individuals are expected to take care of only themselves and their immediate families". Masculinity (MAS) relates to "a preference in society for achievement, heroism, assertiveness, and material rewards for success". Uncertainty avoidance (UA) is demarcated 
as the "degree to which the members of a society feel uncomfortable with uncertainty and ambiguity".

Additional research into Asian contexts and cultures was carried out a decade later and allowed Hofstede to identify two additional dimensions: long-term orientation (LTO) and indulgence (IND) (Hofstede et al. 2010). Long-term orientation (LTO) values societal change, whereas individuals complying with norms and traditions are prevalent in short-term cultures. Indulgence (IND) pertains to those national cultures with individuals "enjoying life and having fun". These six cultural dimensions have been operationalized by means of indices that cover a large number of countries, with the exception of the last two dimensions (i.e. LTO and IND), coverage of these is less extensive.

The theoretical conceptual framework has been the object of several criticisms over time (e.g. McSweeney 2002), however, today most social science scholars still adopt it. Also, it has been embraced by marketing scholars and hospitality marketing researchers to contextualize and interpret their findings. For example, Mattila (1999) finds significant discrepancies in the assessment of hospitality services across Western vs. Eastern travellers (with the former expressing higher evaluations) and used the Hofstede's dimension of "power distance" to make sense of her findings, arguing that Western consumers express higher evaluations because they display lower levels of power distance than Eastern cultures. In their study of Japanese guests, Reisinger and Turner (1999) underline that Japanese customers are interested in personal and extended interactions. Crotts and Erdmann (2000) find that consumers from feminine societies are more tolerant of service failures, while Reisinger and Crotts (2010) shed light on the differentiated reactions of consumers within nations.

Until now, researchers have disregarded the role of cultural factors in the online assessment of hospitality services, with the exception of a few studies (e.g. Gao et al. 2018; Mariani et al. 2019b; Mariani and Predvoditeleva 2019). For instance, Gao et al. (2018) examine the association of power distance with online review ratings and find that the higher the power distance of the online customer, the lower the online ratings. However, previous studies have not considered explicitly the cultural distance construct and variable to understand how the cultural distance between the hospitality service providers and customers might affect online ratings. In this study, following the lead of Kogut and Singh (1988) that embedded the Hofstede's cultural dimensions into a cultural distance metric to study entry mode strategies into foreign markets, we deploy the cultural distance among the service customers and service providers to examine its impact on online customer ratings. Rather than taking into account a specific cultural dimension (e.g., power distance), we rely on cultural distance to proxy cross-national discrepancies across service customers and providers. As service interactions are relational in essence (Grönroos 1978), we argue that cultural distance is an appropriate metric.

We expect that the greater the cultural distance between service customers and service providers, the higher the chance of cultural gaps and differences and, thus, the higher the likelihood that cultural differences might translate into lower levels of satisfaction in online settings. Consequently, we hypothesize that: 
Research Hypothesis : In international settings, the higher the cultural distance between (hospitality) services customers and services providers, the lower the online evaluation (i.e. online ratings) of the services given by customers.

\section{Empirical setting, data and methods}

\subsection{Empirical setting}

To warrant the generalizability of our findings in terms of covering cultural distances between services providers and multiple international services customers, this study was conducted in the third most visited destination city worldwide: London, United Kingdom. London belongs to one of the top ten countries for inbound international tourism flows (UNWTO 2019) and is the most visited destination in terms of international tourism flows (European Cities Marketing 2018).

Both a leisure and a business destination, London was chosen as it exhibits a very large share of international guests, with three out of four overnight stays involving an international traveller in 2016 (European Cities Marketing 2018). The Booking. com population data retrieved for the analysed timeframe reflects this distribution; $60.7 \%$ of the reviews were written by international tourists.

The U.K. capital, London displays a heterogeneous mass of international tourists, with around 101 nationalities visiting. In this work, we focus on almost 715,000 hotel service encounters reflected in online reviews that we retrieved (as explained in the following data section).

\subsection{Data collection and variables}

The online review data of Booking.com was retrieved by the researchers via big data stemming from online reviews, to generate big data analytics (Davenport 2017; Mariani 2019; Mariani and Fosso Wamba 2020) to shed light on consumers' online evaluations of the main hospitality services. Being a popular e-commerce platform for hospitality services, Booking.com encompasses the highest share of certified online reviews globally (Mariani et al. 2019b) and has been identified in previous research as an appropriate data source (as well as Expedia.com) for eWOM research in hospitality (e.g. Gao et al. 2018; Mariani and Borghi 2018). Data was retrieved by means of a crawler developed in the Python programming language; this scraped data for the overall population of online reviews (ORs) related to London-based hotels over the timeframe January 2015 to January 2017. Firm level and online review level data was collected. For the sampling process, using the data scraping (an automated process through which the crawler mimics human behavior when looking for accommodation online in London via Booking.com), we initially obtained a total of 1,228,089 online reviews. We then retained only those reviews that did not display any missing values. In other words, we retained online reviews for which we had complete 
data for the following (sets of) variables: (1) country of origin; (2) Hofstede cultural dimensions; (3) type of trip; (4) presence of text; (5) length of stay. For instance, in those cases where the country of origin (COO) was missing, or the $\mathrm{COO}$ was not covered by the Hofstede dimensions indices, it would have not been possible to compute a cultural distance measure. As such, from the original sample (overall population), we retained a total of 714,836 reviews for which data were complete. Reviewers were from 101 different countries. As we do not use a survey method but build on a big data and data science approach (George et al. 2014; Mariani et al. 2018), our aim was not to get a representative sample of the population, but rather analyse as many online reviews as possible based on the initial population of reviews retrieved. That said, the numerosity of the subsamples of reviews by $\mathrm{COO}$ is largely consistent with the size of the inbound tourism markets to the UK (Visit Britain 2018) and the reviews cover all of the London-based hotels listed on Booking.com at the time of the data scraping.

The hotel online ratings is the dependent variable of the study: they vary in a range of 2.5 to 10.0 . The main independent variable encompasses the cultural distance among the service provider and the countries of origin of the guests. Following the lead of Kogut and Singh (1988), the measure's construction is illustrated in the following equation:

$$
\text { Cultural Distance }{ }_{c p}=\frac{1}{4} \sum_{i=1}^{4} \frac{\left(D_{c i}-D_{p i}\right)^{2}}{v_{i}}
$$

The measure of cultural distance (in the context of service provision) is illustrated in this formula which gauges the cultural distance of the international hospitality service customer $c$ and the hospitality service provider $p$, whereby Dci and Dpi symbolise the i-th Hofstede dimension for the country of origin of the hospitality service customer $c$, and the country of the hospitality service provider $p$, respectively, and $V i$ represents the variance of the relevant Hofstede's dimension in the specific sample under analysis. The cultural distance variable assumes high positive values when service customers exhibit significantly and systematically different cultural traits if compared with service providers; on the other hand, it displays low values (close to zero) when service customers display approximately the same cultural traits as the service providers.

In the footsteps of Gao et al. (2017), the average observed online review score was included in the model specification to take into account the entire rating history of each hospitality firm covered by Booking.com reviews for the destination under analysis. Furthermore, we considered other variables related to reviewers such as the degree of online identity disclosure (i.e. the degree of the reviewer's disclosure of their personal information, such as age), the reviewer's gender, and trip-related variables such as the length of stay (measured in number of nights), the purpose of the trip (if the motivation of the trip was business or leisure), travel group composition (i.e. a dummy variable distinguishing solo travellers vs. other types of travel groups). Last, we deployed several controls at the firm level, covering hotel category (i.e. the number of stars) and whether the hotel 
Table 1 Description of variables

\begin{tabular}{|c|c|}
\hline Variable & Description \\
\hline Rating & $\begin{array}{l}\text { Online rating posted by an online reviewing customer } \\
\text { after consuming/experiencing service }\end{array}$ \\
\hline Cultural Distance (Cultural_Distance) & $\begin{array}{l}\text { The cultural distance between a hotel customer and a } \\
\text { hotel's country of origin gauged by embedding the } \\
\text { Hofstede cultural dimension into the measure used by } \\
\text { Kogut and Singh (1988) }\end{array}$ \\
\hline Observed Average Rating (Obs_Avg_Rating) & $\begin{array}{l}\text { Hotel's review average rating as observed by reviewing } \\
\text { customer at the time when s/he posted his/her review } \\
\text { (see Gao et al. 2018) }\end{array}$ \\
\hline No Identity Disclosure (No_Identity_Disc) & $\begin{array}{l}\text { Dummy variable that is equal to } 1 \text { if the reviewing } \\
\text { customer does not disclose his/her gender and age and } \\
\text { zero otherwise }\end{array}$ \\
\hline Gender (Female) & $\begin{array}{l}\text { Dummy variable that is equal to } 1 \text { if the reviewing cus- } \\
\text { tomer's gender is female and zero otherwise }\end{array}$ \\
\hline Length of Stay (LoS) & $\begin{array}{l}\text { Number of nights spent in the hotel by the reviewing } \\
\text { customer }\end{array}$ \\
\hline Trip Purpose (Leisure) & $\begin{array}{l}\text { It is a dummy variable that is equal to } 1 \text { if the reviewing } \\
\text { customer is travelling for leisure and zero otherwise }\end{array}$ \\
\hline Solo Traveler (solo) & $\begin{array}{l}\text { It is a dummy variable that is equal to } 1 \text { if the reviewing } \\
\text { customer is travelling solo and zero otherwise }\end{array}$ \\
\hline
\end{tabular}

Table 2 Descriptive statistics

\begin{tabular}{llllll}
\hline & Mean & SD & \% of 1 & Min & Max \\
\hline Rating & 7.79 & 1.82 & & 2.50 & 10.00 \\
Cultural_Distance & 1.33 & 1.62 & & 0.00 & 8.58 \\
Obs_Avg_Rating & 7.85 & 0.89 & & 2.50 & 10.00 \\
Length of Stay & 2.43 & 1.69 & & 1.00 & 31.00 \\
No_Identity_Disc & & & 16.19 & 0.00 & 1.00 \\
Gender & & & 39.98 & 0.00 & 1.00 \\
Leisure & & & 84.54 & 0.00 & 1.00 \\
Solo & & & 21.63 & 0.00 & 1.00 \\
Observations & 714,836 & & & & \\
\hline
\end{tabular}

company belonged to a chain or not. The description for each variable is found in Table 1:

The descriptive statistics are presented in Table 2.

Overall, the variables display values of kurtosis and skewness in line with normality assumptions based on non-parametric kernel density estimators. 


\subsection{Data analysis}

The focal research hypothesis was tested adopting multivariate ordinary least squares (OLS) regressions. The latter ones are appropriate when variables show multivariate normality, like in the case examined in this work. We opted for a multivariate ordinary least squares (OLS) over a logistic model (Harrell 2015) as, unlike the ratings on TripAdvisor, the ratings on Booking.com assume a very high number of possible values between 2.5 and 10.0, being the result of the average of the ratings given on the different attributes that are based on the specific Booking.com rating system (Mariani and Borghi 2018; Mellinas et al. 2015). However, we adopted the logistic model to validate our findings that are robust across the two methods. Our model is specified as follows:

$$
\begin{aligned}
\text { Rating }_{c p}= & \beta_{0}+\beta_{1}(\text { Cultural_Distance })_{c p}+\beta_{2}(\text { Obs_Avg_Rating })_{c p}+ \\
& \mathrm{B}_{3}(\text { No_Identity_Disc })_{c p}+\beta_{4}(\text { Gender })_{c p}+\beta_{5}(\text { LoS })_{c p}+\beta_{6}(\text { Leisure })_{c p}+ \\
& \mathrm{B}_{7}(\text { Solo })_{c p}+\beta_{8}(\text { Hotel_Star_Rating })_{c p}+\beta_{9}(\text { Chain })_{c p}+\varepsilon_{c p}
\end{aligned}
$$

Our focal dependent variable, i.e. the online rating (Rating) given by the international hospitality service customer $c$ to the hospitality service provider $p$ was regressed against the independent variables: cultural distance, observed average rating (Obs_Avg_Rating) and control variables such as the reviewer's demographics (e.g. gender), behavioral features (e.g. level of online identity disclosure), as well as factors pertaining to the trip (e.g. length of stay, purpose of trip and travel companions).

\section{Analysis and findings}

An analysis of the results shows that the cultural distance among international hospitality service customers and service providers exerts a significantly negative effect $(\mathrm{p}<0.001)$ on the online review valence (see Table 3$)$. Therefore, our focal research hypothesis is not rejected. This finding suggests that cultural distance is relevant in services encounters in general and hospitality services encounters in particular, and that the country of origin of international customers is a relevant predictor of their online behavior and online ratings. This result corroborates findings in the international marketing literature (e.g. Cleveland et al. 2016). We also measured the elasticity (or better, the marginal effect) of the focal explanatory variable (cultural distance) on our dependent variable (online ratings) and this turned out to be negative (ey/ex $=-0.0134565)$ and significant $(\mathrm{p}<0.001)$. By computing and plotting the marginal effects at different levels of the focal independent variable, we observe that the marginal contribution of cultural distance to online ratings appears to be significant and negative, ranging from 0 (same country and therefore no cultural distance) to $-0.091(\mathrm{p}<0.001)$ when the cultural distance is equal to 8.58 (this is the case of Guatemala that has the highest cultural distance in the sample). 
Table 3 Results of the OLS regression

\begin{tabular}{|c|c|c|}
\hline & Model 1 (baseline) & Model 2 \\
\hline Cultural_distance & & $\begin{array}{l}-0.0754 * * * \\
(0.00122)\end{array}$ \\
\hline Obs_Avg_Rating & & $\begin{array}{l}1.048 * * * \\
(0.00251)\end{array}$ \\
\hline No_Identity_Disc & & $\begin{array}{l}-0.185 * * * \\
(0.00533)\end{array}$ \\
\hline Female & & $\begin{array}{l}0.179 * * * \\
(0.00403)\end{array}$ \\
\hline LoS & & $\begin{array}{l}-0.000432 \\
(0.00117)\end{array}$ \\
\hline Leisure & & $\begin{array}{l}0.356 * * * \\
(0.00612)\end{array}$ \\
\hline Solo & & $\begin{array}{l}0.0382 * * * \\
(0.00537)\end{array}$ \\
\hline One-star hotels & $\begin{array}{l}-1.184 * * * \\
(0.0309)\end{array}$ & $\begin{array}{l}0.117 * * * \\
(0.0276)\end{array}$ \\
\hline Two-star hotels & $\begin{array}{l}-0.800 * * * \\
(0.00998)\end{array}$ & $\begin{array}{l}0.0337 * * * \\
(0.00908)\end{array}$ \\
\hline Three-star hotels & $\begin{array}{l}0.105 * * * \\
(0.00847)\end{array}$ & $\begin{array}{l}0.0114 \\
(0.00753)\end{array}$ \\
\hline Four-star hotels & $\begin{array}{l}0.651 * * * \\
(0.00848)\end{array}$ & $\begin{array}{l}0.0189 * \\
(0.00769)\end{array}$ \\
\hline Five-star hotels & $\begin{array}{l}1.270 * * * \\
(0.0111)\end{array}$ & $\begin{array}{l}0.0312 * * \\
(0.0103)\end{array}$ \\
\hline Constant & $\begin{array}{l}7.513 * * * \\
(0.00777)\end{array}$ & $\begin{array}{l}-0.686 * * * \\
(0.0214)\end{array}$ \\
\hline Chain & Yes & Yes \\
\hline$R^{2}$ & 0.082 & 0.279 \\
\hline Adjusted $R^{2}$ & 0.082 & 0.279 \\
\hline Observations & 714,836 & 714,836 \\
\hline
\end{tabular}

Standard errors in parentheses

$* p<0.05, * * p<0.01, * * * p<0.001$

As far as the reviewer level variables are concerned, the absence of identity disclosure, especially age (for which there are many missing values), seems to negatively influence overall review valence. In other words, online international customers that do not disclose their age or gender give lower ratings then those who do. The described findings are in contrast with previous research (Gao et al. 2018) that, nonetheless, did not provide any justification of their finding. Our interpretation of our results is that reviewers not revealing their identity may feel less constrained than their counterparts in their online evaluations process and, therefore, they could shape their opinions with more freedom and objectivity, thus being potentially 
conservative in their online review ratings. We also find that female customers evaluate hotels higher $(\mathrm{p}<0.001)$ than male customers; this is consistent with previous studies in offline settings (Sparks 1994).

International customers staying more nights, and therefore experiencing a longer service consumption, do not appear to give significantly better or worse ratings; the length of stay does not seem to affect international customers' online behavior and review ratings. International customers travelling for leisure and solo tend to give higher online ratings (the coefficients are both positive and $\mathrm{p}<0.001$ ). Looking at the review level control variables, the observed average rating has a positive and significant effect $(\mathrm{p}<0.001)$, consistent with research showing that social dynamics influence reviewers' ratings (e.g. Gao et al. 2017; Ma et al. 2013). Lastly, we have controlled our results for hospitality firm variables such as hotel class and chain.

\section{Theoretical and managerial implications}

Based on a large dataset encompassing more than 0.7 million Booking.com online reviews produced by hospitality customers visiting the U.K., this study has examined if, and to what extent, the cultural distance among hospitality service providers and international customers affects consumer online rating behaviors and, ultimately, review valence.

There are three key findings that emerge from the empirical analysis. Firstly, the greater the cultural distance of the international service customer and provider, the lower the international customer online review evaluation (i.e. online rating) of hospitality services. Secondly, as online evaluations can be seen as a proxy of online customer satisfaction (Engler et al. 2015; Ho et al. 2017; Liu et al. 2013; Schuckert et al. 2015a, b), our findings indicate that the online satisfaction of international customers is significantly dependent on their cultural values. Consistently, digital platforms call for a more nuanced appreciation of international marketing theories and practices (Cleveland et al. 2016; Laroche et al. 2004, 2006; Nambisan et al. 2019).

Third, the magnitude of the coefficients associated with the service provider category, which is a proxy of the quality of the hospitality service, appears to be still significant. However, the full model specification, including cultural factors (see Model 2 in Table 3), help explain a higher share of the variance of online ratings. This might suggest that online customer satisfaction is driven by a series of factors (both subjective and objective and/or related to the mechanisms of reviewing), including both the quality of the services (such as stars) and other factors such as the cultural distance. Furthermore, we find that international online customers not disclosing their personal information online, probably feel less constrained and, therefore, free to give more conservative evaluations to the reviewed services. As such, model specifications, including both reviewer level and reviewed service features, represent the way ahead to achieving a more rounded understanding of online international customer satisfaction with services. Certainly, cultural differences between service providers and customers, as well as other reviewer level variables such as 
identity disclosure and reviewing behaviors, will need to be embedded in future model specifications.

\subsection{Theoretical contributions}

This work makes multiple contributions to many research streams within marketing literature. First, it contributes to the research stream at the intersection between electronic word-of-mouth (eWOM), digital platforms and big data. To the best of our knowledge, this is one of the first attempts to leverage on large volumes of digital data streams produced in real time and in a variety of forms (i.e. big data) (Pigni et al. 2016) to explain the online behaviors of international customers after service interactions. We contribute to an emerging line of research that makes use of big digital data analytics from digital platforms to shed light on customer satisfaction with services in international settings (e.g. Mariani and Predvoditeleva 2019; Mariani et al. 2019b; Nambisan et al. 2019). Along the lines of Nambisan (2017) and Nambisan et al. (2019), we argue that digital platforms and ecosystems-and the underlying digital transformation that they have brought about, conjointly with the overproduction of online reviews-are partially reshaping international marketing theories as they enable novel forms of (digital) connectivity. These new forms of connectivity affect not only how global and local service providers internationalize their value propositions, but also how they build market knowledge based on digital data analytics (Davenport 2014, 2017; Mariani and Fosso Wamba 2020; Mariani 2019), and create and deliver value to global customers.

Second, this work contributes to cross-cultural and international marketing studies (e.g. de Mooij and Hofstede 2011) in online settings (Gao et al. 2018). We analyse to what extent cultural distance among international services customers and providers in hospitality affects online customer ratings and behaviors. Going beyond the consideration of the mere Hofstede's dimensions, we deploy the cultural distance metric deployed in the 1980s by Kogut and Singh (1988) to reflect and measure the cultural discrepancies of international hospitality service providers and customers. Our findings seem consistent with marketing research, suggesting that culture influences consumers' perceptions and information processing before generating evaluations (Cleveland et al. 2016). The empirical results indicate that online behaviors are partially culturally dependent, offering a clear explanation of the discrepancy in online evaluations of similar hospitality services by hotel guests from different cultural backgrounds, based on the distinctively different cultural values they intentionally or unintentionally share with the national group they belong to.

Third, this study contributes to international marketing theory. Interestingly, we find similarities with international marketing studies investigating the "country of origin effect" and the "cultural distance effect" to explain cross-cultural consumer behavior in offline settings (de Mooij and Hofstede 2011). These similarities seem to strengthen the statement that, despite globalization dynamics and the likely emergence of convergent consumer behaviors across countries (McLeod 2004), national identities are becoming more critical as it is likely that consumers of different 
socio-cultural groups construct and recognize a specific social identity that affects their online behavior.

Furthermore, our findings corroborate international market segmentation theory in general (Cleveland et al. 2016; Dibb and Simkin 2001) and contribute to the research stream pertaining to the divide between practice and research in segmentation studies (Dolnicar and Lazarevski 2009).

From a theoretical point of view, our work suggests that international hospitality customers are not homogeneous, but rather consist of distinctively different segments (as our cultural distance metric suggests). The underlying cultural dimensions might represent segmentation variables that could generate further insights, rather than a mere country of origin segmentation that is used sometimes in practice by hospitality marketers (Cvelbar et al. 2017; Mazanec et al. 2015; Seabra et al. 2013). Therefore, marketing segmentation research in hospitality services (Dolnicar 2004), especially if carried out in online settings, would enormously benefit from taking into account human values (Rokeach 1973), and especially cultural values (Hofstede 1980).

\subsection{Managerial implications}

The present work presents multiple practical implications for the following groups of individuals: (i) international service providers in the hospitality sector and, more generally, practitioners and managers in services industries; (ii) developers, administrators and managers of online review platforms and digital platforms in general; (iii) international customers of (hospitality) services.

International service providers in the hospitality sector and, more generally, managers in the services industries could progressively combine traditional techniques of evaluating service quality (including the SERVQUAL (Zeithaml et al. 1996) and SERVPERF (Cronin and Taylor 1992) to more updated techniques deploying digital data stemming from online review platforms. Hence, triangulation of small and big data from online reviews (Mariani et al. 2018) might allow for a more comprehensive evaluation of service quality in hospitality settings. Second, they could adopt this study's results to better understand international customers' perceived quality of hospitality services based on their country of origin and on the cultural distance between the service providers and customers. In this way, managers could gain precious knowledge to personalize the hotel's offering and tailor communication during and after the service encounter. Third, the findings seem to implicitly suggest that similar cultural traits are associated with similar international customers' online behaviors. As such, it would be recommended to segment societal groups of customers by cultural dimensions. This type of segmentation could call for the development of different targeted marketing mixes based on groups of nationalities rather than based on "traditional" individual nationalities (Grier and Brumbaugh 1999). Fourth, hotel managers should pay more attention to those national groups that display the higher cultural distance vis-à-vis that of the hotel. As such, a hotel's management response and response strategy (Xie et al. 2016) might be calibrated based on the reviewer's nationality. 
As far as developers, administrators and managers of online review platforms are concerned, the findings of this research are extremely relevant for digital platforms that increasingly operate in multi-country and international environments, and that have to interact with multiple national cultures that could be distinctively different vis-à-vis the culture of the service providers. First, the findings of this work are particularly germane for e-commerce websites (e.g. Expedia and Booking.com) as they have to optimize continuously the algorithms underlying their recommender systems to boost bookings on their websites and, ultimately, generate higher revenues. Their recommender systems might be further optimized and perfected by, not only recommending reviews from the same country to their online readers (and prospective customers), but also recommending reviews from countries that are similar across one or more of the cultural dimensions, with a specific emphasis on the individual Hofstede's dimensions and/or combinations of them. Second, online travel review platforms such as TripAdvisor (its reviews are not certified; reviews are not related to real stays and anyone can post a review on the website), could work on algorithms similar to those used by Booking.com or Expedia that filter reviews and, therefore, help international customers to identify useful reviews based on a similar country of origin. This is, to a certain extent, one of the major issues of online reviews as the residence of the reviewer (as well as other identity information) is often missing.

As far as implications for international customers are concerned, OTAs such as Booking.com should keep on investing in mechanisms enhancing the interaction between online consumers belonging to a common national or social group (Zeugner-Roth et al. 2015), as purchasing decisions depend on the degree of perceived closeness between the reader and the writers of a review (Vásquez 2014). Second, it is suggested that if international customers use independent online review platforms (often lacking country of origin/residence information), they should focus on those reviews written by online reviewers from the same country or displaying a similar cultural background.

\section{Conclusion and future research}

The present work has added to multiple research streams within the international marketing body of literature, with emphasis on cross-cultural studies of consumer behaviour in online settings and to the nascent eWOM research stream pertaining to the impact of cultural distance on online reviews, hence contributing to eWOM research in the services sectors and, more specifically, travel, hospitality and tourism services (Cantallops and Salvi 2014).

Overall, this research analyses conjointly how online international customers' characteristics (e.g. cultural traits, demographics) and the features of services providers (e.g. service category) affect online international customers' ratings. We contribute to an emerging line of research that makes use of big digital data analytics from digital platforms to shed light on customer satisfaction with services in international settings (e.g. Mariani et al. 2019b; Mariani and Fosso Wamba 2020; Nambisan et al. 2019). 
First, leveraging a sample of more than 0.7 million online travel reviews, we have analyzed how the cultural distance of international hospitality service customers and providers affects online customer satisfaction across countries. More specifically, the greater the cultural distance between the international service customer and provider, the lower the international customer's online review evaluation (i.e. online rating) of hospitality services. This finding suggests that international customers' online evaluation of services is dependent on the cultural distance of service customers and service providers in international settings.

Second, as online evaluations can be seen as a proxy of online customer satisfaction (Engler et al. 2015; Ho et al. 2017; Liu et al. 2013; Schuckert et al. 2015a, b), our findings indicate that international customers' online satisfaction is significantly dependent on the cultural values of customers that are captured through the cultural dimensions developed by Hofstede. Therefore, this result seems to suggest that online environments shaped by digital platforms and technologies, call for a more nuanced appreciation of international marketing theories and practices (Cleveland et al. 2016; Laroche et al. 2004, 2006; Nambisan et al. 2019). Of course, this contribution might be embedded in the wider debate revolving around the extent to which online ratings are correlated with actual overall customer satisfaction with the service and its attributes (e.g. Limberger et al. 2014).

Third, the magnitude of the coefficients associated with the service provider category, which is a proxy of the quality of the hospitality service, still appears significant. However, when including cultural factors in the model specification, the model explains a higher share of the variance of online ratings. This might suggest that online customer satisfaction is driven by a series of factors (both subjective and objective and/or related to the mechanisms of reviewing), including both the quality of the services (such as stars) and other factors (such as cultural distance). For instance, in our study we find that when online international customers do not disclose their personal information, they are more likely-due to the higher anonymity of their online evaluation - to be less constrained and therefore feel free to give more conservative evaluations to the reviewed services. As such, model specifications (including both reviewer level and reviewed service features) represent the way ahead to achieve a more rounded understanding of online international customer satisfaction with services. Certainly, cultural differences between service providers and customers, as well as other reviewer level variables (such as identity disclosure and reviewing behaviors) will need to be embedded in future model specifications.

Our work has contributed to the development of the marketing literature in multiple ways. First, it has contributed to an emerging line of research that makes use of big digital data analytics from digital platforms to shed light on customer satisfaction with services in international settings (e.g. Mariani et al. 2019b; Nambisan et al. 2019). Accordingly, we contend that digital ecosystems and platforms are partially reshaping international marketing theories as they enable novel forms of (digital) connectivity. Second, this study has contributed to the emerging research stream of cross-cultural and international marketing studies in online settings (e.g. Gao et al. 2018). We emphasize that culture influences consumers' perceptions and information processing before generating evaluations (Cleveland et al. 2016) and that online behaviors are partially culturally dependent. Third, this work has contributed to 
international marketing theory by suggesting that, despite globalization dynamics and the likely emergence of convergent consumer behaviors across countries (McLeod 2004), national identities are, however, becoming more critical. Furthermore, our findings corroborate international market segmentation theory in general (Cleveland et al. 2016; Dibb and Simkin 2001) and contribute to the research stream pertaining to the divide between practice and research in segmentation studies (Dolnicar and Lazarevski 2009). We suggest that international hospitality customers are not homogeneous, but rather consist of distinctively different segments, as our cultural distance metric suggests. Therefore, marketing segmentation research in hospitality services (Dolnicar 2004), especially if carried out in online settings, would enormously benefit from taking into account human values (Rokeach 1973), and especially cultural values (Hofstede 1980).

Though this work offers both valuable theoretical contributions and practical and managerial implications, it displays a few limitations. Firstly, we might enhance the model specification by making it more comprehensive through the inclusion of variables such as the submission device deployed to write the review (Mariani et al. 2019c). Moreover, the model might be compared to other models where the dependent variable would be the ratings of the different hospitality service attributes (such as location, cleanliness, staff, etc.); however, this would require the creation of a more sophisticated crawler as Booking.com data cannot be scraped solely based on APIs. Second, future research might try to examine if the findings hold regardless of the online review platform deployed (for instance, comparing Booking. com reviews with Expedia and Tripadvisor reviews). Third, in order to further generalize our findings, it would be interesting to extend our study beyond London and consider other (less attractive and less known) destinations to understand whether there are sector specificities that could yield differentiated results. Indeed, we might argue that hospitality services are rather globalized and internationalized, but not necessarily this would hold for other services (such as medical or financial services). Overall, this suggests that when examining the effects of cultural distance on online review ratings across different places/industries, scholars should be cautious. The results match with recent research that measures the impact of cultural orientations on the deployment of electronic word of mouth of customers (Nath et al. 2018). Finally, future studies might put together online review ratings and text analytics to shed light on the extent to which text analytics vary across cultural groups and if they interact with online review ratings across cultural groups.

Acknowledgements We would like to thank the Associate Editors and the anonymous reviewers for their helpful and constructive comments. We are grateful to two colleagues for their advice on earlier versions of the paper and to Emma Lang and Kathryn Pilgrem for their assistance with professional copyediting and design.

Open Access This article is licensed under a Creative Commons Attribution 4.0 International License, which permits use, sharing, adaptation, distribution and reproduction in any medium or format, as long as you give appropriate credit to the original author(s) and the source, provide a link to the Creative Commons licence, and indicate if changes were made. The images or other third party material in this article are included in the article's Creative Commons licence, unless indicated otherwise in a credit line to the material. If material is not included in the article's Creative Commons licence and your intended use is not permitted by statutory regulation or exceeds the permitted use, you will need to obtain permission 
directly from the copyright holder. To view a copy of this licence, visit http://creativecommons.org/licen ses/by/4.0/.

\section{References}

Allik, J., \& Realo, A. (2004). Individualism-collectivism and social capital. Journal of Cross-Cultural Psychology, 35(1), 29-49.

Appelt, L. (2010). Literature review: Online consumer product ratings and reviews. Interaction and Interface Design, 1-13.

Ayeh, J. A., Au, N., \& Law, R. (2013). Predicting the intention to use consumer-generated media for travel planning. Tourism Management, 35, 132-143.

Bagozzi, R. P., Wong, N., Abe, S., \& Bergami, M. (2000). Cultural and situational contingencies and the theory of reasoned action: application to fast food restaurant consumption. Journal of Consumer Psychology, 9(2), 97-106.

Borghi, M., \& Mariani, M. M. (2020). Service robots in online reviews: Online robotic discourse. Annals of Tourism Research, 103036.

Breidbach, C., Brodie, R., \& Hollebeek, L. D. (2014). Beyond virtuality: from engagement platforms to engagement ecosystems. Managing Service Quality, 24(6), 592-611.

Cantallops, A. S., \& Salvi, F. (2014). New consumer behavior: a review of research on eWOM and hotels. International Journal of Hospitality Management, 36, 41-51.

Casadesus-Masanell, R., \& Hałaburda, H. (2014). When does a platform create value by limiting choice? Journal of Economics \& Management Strategy, 23(2), 259-293.

Chau, P. Y. K., Cole, M., Massey, A. P., Montoya-Weiss, M., \& O'Keefe, R. M. (2002). Cultural differences in the online behavior of consumers. Communication of ACM, 45, 138-143.

Chen, R. X. Y., Cheung, C., \& Law, R. (2012). A review of the literature on culture in hotel management research: what is the future? International Journal of Hospitality Management, 31(1), 52-65.

Cleveland, M., Rojas-Méndez, J. I., Laroche, M., \& Papadopoulos, N. (2016). Identity, culture, dispositions and behavior: a cross-national examination of globalization and culture change. Journal of Business Research, 69, 1090-1102.

Cronin, J. J., Jr., \& Taylor, S. A. (1992). Measuring service quality: a reexamination and extension. Journal of Marketing, 56(3), 55-68.

Crotts, J. C., \& Erdmann, R. (2000). Does national culture influence consumers' evaluation of travel services? A test of Hofstede's model of cross-cultural differences. Managing Service Quality: An International Journal, 10(6), 410-419.

Cvelbar, L. K., Grün, B., \& Dolnicar, S. (2017). Which hotel guest segments reuse towels? Selling sustainable tourism services through target marketing. Journal of Sustainable Tourism, 25(7), 921-934.

Daughtery, T., Eastin, M., \& Bright, L. (2008). Exploring consumer motivations for creating user-generated content. Journal of Interactive Advertising, 8(2), 16-25.

Davenport, T. H. (2014). How strategists use "big data" to support internal business decisions, discovery and production. Strategy and Leadership, 42(4), 45-50.

Davenport, T. H. (2017). How analytics has changed in the last 10 years. Harvard Business Review, 28, 217.

de Mooij, M., \& Hofstede, G. (2011). Cross-cultural consumer behavior: a review of research findings. Journal of International Consumer Marketing, 23, 181-192.

Dibb, S., \& Simkin, L. (2001). Market segmentation: diagnosing and treating the barriers. Industrial Marketing Management, 30(8), 609-625.

Dolnicar, S. (2004). Beyond 'commonsense segmentation': a systematics of segmentation approaches in tourism. Journal of Travel Research, 42(3), 244-250.

Dolnicar, S., \& Lazarevski, K. (2009). Methodological reasons for the theory/practice divide in market segmentation. Journal of Marketing Management, 25(3/4), 357-373.

Engler, T. H., Winter, P., \& Schulz, M. (2015). Understanding online product ratings: a customer satisfaction model. Journal of Retailing and Consumer Services, 27, 113-120.

European Cities Marketing. (2018). ECM benchmarking report 17/18 (14th ed.). Dijon: ECM. 
Ek Styvén, M., Mariani, M. M., \& Strandberg, C. (2020). This is my hometown! the role of place attachment, congruity, and self-expressiveness on residents' intention to share a place brand message online. Journal of Advertising. https://doi.org/10.1080/00913367.2020.1810594.

Filieri, R., Alguezaui, S., \& McLeay, F. (2015). Why do travelers trust TripAdvisor? Antecedents of trust towards consumer-generated media and its influence on recommendation adoption and word of mouth. Tourism Management, 51, 174-185.

Gao, B., Hu, N., \& Bose, I. (2017). Follow the herd or be myself? an analysis of consistency in behavior of reviewers and helpfulness of their reviews. Decision Support Systems, 95, 1-11.

Gao, B., Li, X., Liu, S., \& Fang, D. (2018). How power distance affects online hotel ratings: the positive moderating roles of hotel chain and reviewers' travel experience. Tourism Management, 65, 176-186.

Gensler, S., Völckner, F., Liu-Thompkins, Y., \& Wiertz, C. (2013). Managing brands in the social media environment. Journal of Interactive Marketing, 27(4), 242-256.

George, G., Haas, M. R., \& Pentland, A. (2014). Big data and management. Academy of Management Journal, 57(2), 321-326.

Gretzel, U., \& Yoo, K. (2008). Use and impact of online travel reviews. In P. O'Connor, W. Hopken, \& U. Gretzel (Eds.), Information and communication technologies in tourism (Vol. 2, pp. 35-46). Wien/ New York: Springer-Verlag.

Grier, S., \& Brumbaugh, A. (1999). Noticing cultural differences: ad meanings created by target and nontarget markets. Journal of Advertising, 28(1), 79-93.

Grönroos, C. (1978). A service-orientated approach to marketing of services. European Journal of Marketing, 12(8), 588-601.

Harrell, F. E., Jr. (2015). Regression modeling strategies: with applications to linear models, logistic and ordinal regression, and survival analysis (2nd ed.). Cham: Springer International Publishing.

Hennig-Thurau, T., Gwinner, K. P., Walsh, G., \& Gremler, D. D. (2004). Electronic word-of-mouth via consumer-opinion platforms: what motivates consumers to articulate themselves on the internet? Journal of Interactive Marketing, 18(1), 38-52.

Ho, Y. C., Wu, J., \& Tan, Y. (2017). Disconfirmation effect on online rating behavior: a structural model. Information Systems Research, 28(3), 626-642.

Hofstede, G. (1980). Culture's consequences: International differences in work-related values. Beverly Hills/London: Sage Publications.

Hofstede, G. (2001). Culture's consequences: comparing values, behaviors, institutions, and organizations across nations (2nd ed.). Thousand Oaks: Sage Publications.

Hofstede, G. (2011). Dimensionalizing cultures: the Hofstede Model in context. Online Readings in Psychology and Culture. https://doi.org/10.9707/2307-0919.1014.

Hofstede, G., Hofstede, G. J., \& Minkov, M. (2010). Cultures and organizations: software of the mind. Intercultural cooperation and its importance for survival (3rd ed.). New York: McGraw-Hill.

Huang, S. S., \& Crotts, J. (2019). Relationships between Hofstede's cultural dimensions and tourist satisfaction: a cross-country cross-sample examination. Tourism Management, 72, 232-241.

Huff, L., \& Kelley, L. (2003). Levels of organizational trust in individualist versus collectivist societies: a seven-nation study. Organization Science, 14(1), 81-90.

Jin, L., Hu, B., \& He, Y. (2014). The recent versus the out-dated: an experimental examination of the time-variant effects of online consumer reviews. Journal of Retailing, 90(4), 552-566.

Key, T. M. (2017). Domains of digital marketing channels in the sharing economy. Journal of Marketing Channels, 24(1-2), 27-38.

Kogut, B., \& Singh, H. (1988). The effect of national culture on the choice of entry mode. Journal of International Business Studies, 19(3), 411-432.

Langan, R., Besharat, A., \& Varki, S. (2017). The effect of review valence and variance on product evaluations: an examination of intrinsic and extrinsic cues. International Journal of Research in Marketing, 34(2), 414-429.

Laroche, M., Kalamas, M., \& Cleveland, M. (2006). "I" versus "we": how individualists and collectivists use information sources to formulate their service expectations. International Marketing Review, 22(3), 279-308.

Laroche, M., Ueltschy, L. C., Shuzo, A., \& Cleveland, M. (2004). Service quality perceptions and customer satisfaction: evaluating the role of culture. Journal of International Marketing, 12(3), 58-85.

Limberger, P. F., Anjos, D. F. A., de Meira, S. J. V., \& Anjos, D. S. J. (2014). Satisfaction in hospitality on TripAdvisor com: an analysis of the correlation between evaluation criteria and overall satisfaction. Tourism \& Management Studies., 10(1), 59-65. 
Liu, S., Law, R., Rong, J., Li, G., \& Hall, J. (2013). Analyzing changes in hotel customers' expectations by trip mode. International Journal of Hospitality Management, 34, 359-371.

Liu, Y., Teichert, T., Rossi, M., Li, H., \& Hu, F. (2017). Big data for big insights: investigating languagespecific drivers of hotel satisfcation with 412,784 user-genertaed reviews. Tourism Management, 59, 554-563.

Ludwig, S., de Ruter, K., Friedman, M., Bruggen, E. C., Wetzels, M., \& Pfann, G. (2013). More than words: the influence of affective content and linguistic style matches on line reviews on conversion rates. Journal of Marketing, 77, 87-103.

Ma, X., Khansa, L., Deng, Y., \& Kim, S. S. (2013). Impact of prior reviews on the subsequent review process in reputation systems. Journal of Management Information Systems, 30(3), 279-310.

Mariani, M. (2019). Big Data and analytics in tourism and hospitality: a perspective article. Tourism Review, 75(1), 299-303.

Mariani, M., Borghi, M. (2019). Industry 4.0: A bibliometric review of its managerial intellectual structure and potential evolution in the service industries. Technological Forecasting and Social Change, 149, 119752.

Mariani, M. M., Baggio, R., Fuchs, M., \& Höpken, W. (2018). Business intelligence and big data in hospitality and tourism: a systematic literature review. International Journal of Contemporary Hospitality Management, 30(10), 3514-3554.

Mariani, M. M., \& Borghi, M. (2018). Effects of the Booking.com rating system: bringing hotel class into the picture. Tourism Management, 66, 47-52.

Mariani, M. M., Borghi, M. (2020). Online review helpfulness and firms' financial performance: An empirical study in a service industry. International Journal of Electronic Commerce, 24(4), $421-449$.

Mariani, M. M., Borghi, M., \& Kazakov, S. (2019a). The role of language in the online evaluation of hospitality service encounters: an empirical study. International Journal of Hospitality Management, $78,50-58$.

Mariani, M. M., Di Fatta, G., \& Di Felice, M. (2019b). Understanding customer satisfaction with services by leveraging big data: the role of services attributes and consumers' cultural background. IEEE Access, 7, 8195-8208.

Mariani, M. M., Borghi, M., Gretzel, U. (2019c). Online reviews: Differences by submission device. Tourism Management, 70, 295-298.

Mariani, M., Ek Styven, M., \& Ayeh, J. K. (2019d). Using facebook for travel decision-making: an international study of antecedents. International Journal of Contemporary Hospitality Management, 31(2), 1021-1044.

Mariani, M., \& Predvoditeleva, M. (2019). How do online reviewers' cultural traits and perceived experience influence hotel online ratings? An empirical analysis of the Muscovite hotel sector. International Journal of Contemporary Hospitality Management, 31(12), 4543-4573.

Mariani, M. M., \& Visani, F. (2019). Embedding eWOM into efficiency DEA modelling: An application to the hospitality sector. International Journal of Hospitality Management, 80, 1-12.

Mariani, M. M., \& Wamba, S. F. (2020). Exploring how consumer goods companies innovate in the digital age: The role of big data analytics companies. Journal of Business Research, 121, 338-352.

Mattila, A. S. (1999). The role of culture and purchase motivation in service encounter evaluations. Journal of Services Marketing, 13(4/5), 376-389.

Mattila, A. S. (2000). The impact of culture and gender on customer evaluations of service encounters. Journal of Hospitality \& Tourism Research, 24(2), 263-273.

Mazanec, J. A., Crotts, J. C., Gursoy, D., \& Lu, L. (2015). Homogeneity versus heterogeneity of cultural values: an item-response theoretical approach applying Hofstede's cultural dimensions in a single nation. Tourism Management, 48, 299-304.

McCleary, K. W., Choi, B. M., \& Weaver, P. A. (1998). A comparison of hotel selection criteria between US and Korean business travelers. Journal of Hospitality \& Tourism Research, 22(1), 25-38.

McLeod, D. (2004). Tourism, globalization and cultural change: an island community perspective. New York: Channel View.

McSweeney, B. (2002). The essentials of scholarship: a reply to Geert Hofstede. Human Relations, 55(11), 1363-1372.

Mellinas, J. P., María-Dolores, S.-M. M., \& Garcia, J. J. B. (2015). Booking.com: the unexpected scoring system. Tourism Management, 49, 72-74.

Nambisan, S., Lyytinen, K., Majchrzak, A., \& Song, M. (2017). Digital innovation management: reinventing innovation management research in a digital world. MIS Quarterly, 41(1), 223-238. 
Nambisan, S., Zahra, S., \& Luo, Y. (2019). Global platforms and ecosystems: implications for international business theories. Journal of International Business Studies, 50, 1464-1486.

Nath, P., Devlin, J., \& Reid, V. (2018). The effects of online reviews on service expectations: do cultural value orientations matter? Journal of Business Research, 90, 123-133.

Parker, G. G., Van Alstyne, M. W., \& Choudary, S. P. (2016). Platform revolution: how networked markets are transforming the economy. W.W: Norton \& Company.

Pigni, F., Piccoli, G., \& Watson, R. (2016). Digital data streams: creating value from the real-time flow of big data. California Management Review, 58(3), 5-25.

Pillai, R., Sivathanu, B., Mariani, M. M., Rana, N. P., Yang, B., \& Dwivedi, Y. (2020). Adoption of AIempowered Industrial Robots in Auto Component Manufacturing Companies. Production Planning \& Control.

Reisinger, Y., \& Crotts, J. (2010). Applying Hofstede's national culture measures in tourism research: illuminating issues of divergence and convergence. Journal of Travel Research, 49(2), 153-164.

Reisinger, Y., \& Turner, L. (1999). A cultural analysis of Japanese tourists: challenges for tourism marketers. European Journal of Marketing, 33(11/12), 1203-1227.

Rokeach, M. (1973). The nature of human values. New York: Free press.

Rowley, J. (2008). Understanding digital content marketing. Journal of Marketing Management, 24(5-6), $517-540$.

Schuckert, M., Liu, X., \& Law, R. (2015a). Hospitality and tourism online reviews: recent trends and future directions. Journal of Travel \& Tourism Marketing, 32(5), 608-621.

Schuckert, M., Liu, X., \& Law, R. (2015b). A segmentation of online reviews by language groups: how English and non-English speakers rate hotels differently. International Journal Hospitality Management, 48, 143-149.

Schumann, J., Wangenheim, F. V., Stringfellow, A., Yang, Z., Blazevic, V., Praxmarer, S., et al. (2010). Cross-cultural differences in the effect of received word-of-mouth referral in relational service exchange. Journal of International Marketing, 18(3), 62-80.

Seabra, C., Dolnicar, S., Abrantes, J. L., \& Kastenholz, E. (2013). Heterogeneity in risk and safety perceptions of international tourists. Tourism Management, 36, 502-510.

Singh, S., Ratchford, B. T., \& Prasad, A. (2014). Offline and online search in used durables markets. Journal of Retailing, 90(3), 301-320.

Singh, N., Zhao, H., \& Hu, X. (2003). Cultural adaptation on the web: a study of American companies' domestic and Chinese websites. Journal of Global Information Management, 11, 63-80.

Sparks, B. A. (1994). Communicative aspects of the service encounter. Hospitality Research Journal, 17(2), 39-50.

Tang, L. (2017). Mine your customers or mine your business: the moderating role of culture in online word-of-mouth reviews. Journal of International Marketing, 25(2), 88-110.

UNWTO. (2019). World Tourism Barometer, 17(1). Retrieved 2 February, 2019. http://cf.cdn.unwto.org/ sites/all/files/pdf/unwto_barom19_01_january_excerpt.pdf.

van Hoorn, A. (2015). Individualist-collectivist culture and trust radius: a multilevel approach. Journal of Cross-Cultural Psychology, 46(2), 269-276.

Vásquez, C. (2014). The discourse of online consumer reviews. London: Bloomsbury Publishing.

Visit Britain. (2018). Inbound tourism trends by market. Retrieved 20 August, 2020. www.visitbrita in.org/inbound-tourism-trends.

Xie, K. L., Zhang, Z., Zhang, Z., Singh, A., \& Lee, K. L. (2016). Effects of managerial response on consumer eWOM and hotel performance: evidence from TripAdvisor. International Journal of Contemporary Hospitality Management, 28(9), 2013-2034.

Yamagishi, T., Cook, K., \& Motoki, W. (1998). Uncertainty, trust, and commitment formation in the United States and Japan. American Journal of Sociology, 104(1), 165-194.

Yang, Y., Park, S., \& Hu, X. (2018). Electronic word of mouth and hotel performance: a meta-analysis. Tourism Management, 67, 248-260.

Yun, G. W., Park, S.-Y., \& Ha, L. (2008). Influence of cultural dimensions on online interactive review feature implementations: A comparison of Korean and U.S. retail web sites. Journal of Interactive Marketing, 22(3), 40-50.

Zeithaml, V. A., Berry, L. L., \& Parasuraman, A. (1996). The behavioral consequences of service quality. The Journal of Marketing, 60, 31-46.

Zeugner-Roth, K. P., Žabkar, V., \& Diamantopoulos, A. (2015). Consumer ethnocentrism, national identity, and consumer cosmopolitanism as drivers of consumer behavior: a social identity theory perspective. Journal of International Marketing, 23(2), 25-54. 
Zhu, F., \& Zhang, X. (2010). Impact of online consumer reviews on sales: the moderating role of product and consumer characteristics. Journal of Marketing, 74(2), 133-148.

Publisher's Note Springer Nature remains neutral with regard to jurisdictional claims in published maps and institutional affiliations.

Dr. Marcello M. Mariani is a Full Professor of Management and Entrepreneurship at the Henley Business School, University of Reading (UK) and member of the Henley Center for Entrepreneurship and the European Institute for Advanced Studies in Management. His current research interests include big data and analytics, eWOM, digital business models, AI, IoT, automation and coopetition strategies in service industries. He has authored more than 100 publications. His researches have been published in Industrial Marketing Management, Journal of Business Research, Journal of Advertising, Industrial and Corporate Change, Psychology \& Marketing, Long Range Planning, Technological Forecasting and Social Change, International Journal of Electronic Commerce, European Accounting Review, Production Planning \& Control, Tourism Management, Annals of Tourism Research, Journal of Travel Research, International Journal of Contemporary Hospitality Management, International Journal of Hospitality Management, International Studies in Management and Organizations, and more.

Dr. Michela Matarazzo is Professor of International Business at G. Marconi University of Rome where she serves as Director of the first level Master degree in Global Marketing and Foreign Trade. She has been an elected board member at the Società Italiana Management (2013-2018). She has served (and currently serves) as Track Co-chair at several conferences. Her research interests include international business with a special focus on consumer behaviour, country image, international corporate reputation, SMEs' internationalization and market entry modes, also in relation to the digital context. She has authored, co-authored, more than 80 publications, including journal articles, conference papers, book chapters and 3 books on firms' internationalization and cross-border acquisitions. 